\title{
Exercise for Healthy Lungs
}

\author{
Meenu Singh ${ }^{1} \cdot$ Manvi Singh $^{2}$
}

Received: 16 July 2019 / Accepted: 17 July 2019 / Published online: 29 August 2019

(C) Dr. K C Chaudhuri Foundation 2019

Exercise has been known to prolong life and improve mental health in a large number of chronic diseases. A recently published study went so far to say that exercise makes one happier than money ever can! [1]. So this intervention is a win-win for all stakeholders, including the children with cystic fibrosis (CF).

Decreased bone mineral density or osteoporosis is a well known complication of CF. It usually occurs in adulthood and is partly due to the failure to achieve peak bone mass during puberty. The causal factors include severe lung disease, malnutrition, vitamin and mineral deficiency, decreased physical activity, delayed puberty, diabetes and glucocorticoid therapy [2].

This issue of the Journal carries a novel study by Gupta et al. [3], which brings out certain peculiarities in children with $\mathrm{CF}$ in resource limited Indian settings. A cohort of 52 children with $\mathrm{CF}$ were enrolled and randomized. The mean age of the cohort was around $12 \mathrm{y}$. Most of the children were malnourished with low vitamin D levels at baseline. Introduction of an exercise regimen did not improve their bone mineral density scores. It should be noted that peak bone mass occurs around $15 \mathrm{y}$ in CF patients compared with $30 \mathrm{y}$ in non-CF individuals. So these children were probably around the peak of their bone mineral density, depending on their pubertal status. Aggressive nutritional rehabilitation thoughout the early years and

Meenu Singh

meenusingh4@gmail.com

1 Division of Pediatric Pulmonology, Department of Pediatrics, Advanced Pediatrics Center, Postgraduate Institute of Medical Education and Research, Chandigarh, India

2 Center for Evidence-Based Child Health, Department of Pediatrics, Advanced Pediatrics Center, Postgraduate Institute of Medical Education and Research, Chandigarh, India optimization of the vitamin D levels, preferably titerated to the upper range of normal should be considered the best strategy to prevent osteoporosis. Pubertal delay beyond $14 \mathrm{y}$ should also be investigated and treated as it contributes to osteoporosis, and it might add to the psychological problems coping with a chronic disease at this vulnerable age. Vitamin $\mathrm{K}$ is also an essential cofactor in bone turnover and should be routinely supplemented in children with $\mathrm{CF}$.

The intervention group with exercises did show a significant improvement in quality of life and exercise capacity, which are very important indicators of well being in children with chronic diseases like CF. A Cochrane systematic review updated in 2017 reports the effect of exercise in patients with CF. This systematic review included 15 studies and none of these reported data on the outcome of bone health [4]. The exercise regimens and durations were extremely heterogeneous across the studies included. The authors found the most consistent effect on exercise capacity with unclear effects on pulmonary function and health related quality of life. They concluded that exercise training should be continued as a part of routine care of patients with $\mathrm{CF}$ as there is some evidence of it promoting aerobic fitness, with no negative consequences. They also pointed to the need of conducting good quality randomized controlled trials (RCTs) to further answer these questions.

So while it remains certain that weight bearing exercises should be encouraged in children with $\mathrm{CF}$, generic instructions to exercise are likely to go unheeded in most cases. A structured supervised exercise regimen as was provided in this study should be prescribed with measures to ensure compliance. Exercise is frequently overlooked and underutilized in favour of pharmacological interventions. It is time to change that. As they say "A good physician treats the disease, a great physician treats the patient who has the disease." 


\section{Compliance with Ethical Standards}

Conflict of Interest None.

\section{References}

1. Gradari S, Pallé A, McGreevy KR, Fontán-Lozano Á, Trejo JL. Can exercise make you smarter, happier, and have more neurons? A hormetic perspective. Front Neurosci [Internet]. Available at: https://www.ncbi.nlm.nih.gov/pmc/articles/PMC4789405/ Accessed 4 July 2019.
2. Peebles A, Maddison J. Cystic fibrosis care: a practical guide. Edinburgh: Elsevier Churchill Livingstone; 2005. p. 336.

3. Gupta S, Mukherjee A, Lodha R, et al. Effects of exercise intervention program on bone mineral accretion in children and adolescents with cystic fibrosis: a randomized controlled trial. Indian J Pediatr. 2019. https://doi.org/10.1007/s12098-01903019-x.

4. Radtke T, Nevitt SJ, Hebestreit H, Kriemler S. Physical exercise training for cystic fibrosis. Cochrane Database Syst Rev. 2017: CD002768.

Publisher's Note Springer Nature remains neutral with regard to jurisdictional claims in published maps and institutional affiliations. 